\title{
Kennishiaten en toch Beslissen
}

Citation for published version (APA):

Vrieze, K. (1995). Kennishiaten en toch Beslissen. Universiteit Maastricht. https://doi.org/10.26481/spe.19951117kv

Document status and date:

Published: 17/11/1995

DOI:

10.26481/spe.19951117kv

Document Version:

Publisher's PDF, also known as Version of record

\section{Please check the document version of this publication:}

- A submitted manuscript is the version of the article upon submission and before peer-review. There can be important differences between the submitted version and the official published version of record.

People interested in the research are advised to contact the author for the final version of the publication, or visit the DOI to the publisher's website.

- The final author version and the galley proof are versions of the publication after peer review.

- The final published version features the final layout of the paper including the volume, issue and page numbers.

Link to publication

\footnotetext{
General rights rights.

- You may freely distribute the URL identifying the publication in the public portal. please follow below link for the End User Agreement:

www.umlib.nl/taverne-license

Take down policy

If you believe that this document breaches copyright please contact us at:

repository@maastrichtuniversity.nl

providing details and we will investigate your claim.
}

Copyright and moral rights for the publications made accessible in the public portal are retained by the authors and/or other copyright owners and it is a condition of accessing publications that users recognise and abide by the legal requirements associated with these

- Users may download and print one copy of any publication from the public portal for the purpose of private study or research.

- You may not further distribute the material or use it for any profit-making activity or commercial gain

If the publication is distributed under the terms of Article $25 \mathrm{fa}$ of the Dutch Copyright Act, indicated by the "Taverne" license above, 


\title{
ME \\ $\checkmark A B$ \\ 975
}

\section{Kennishiaten en toch Beslissen}

Een pleidooi voor een Macromodel Volksgezondheid

\author{
Rede
}

Uitgesproken bij de aanvaarding van

het ambt van hoogleraar in de

Mathematische Besliskunde aan de

Rijksuniversiteit Limburg

op 17 november 1995

door

Koos Vrieze 
Deze rede draag ik op aan

mijn ouders en mijn broer Harry

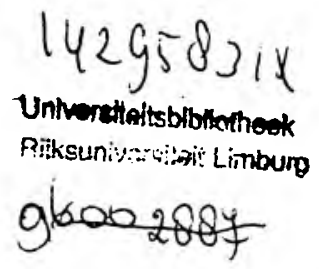

The case for my life, or for that of anyone else who has been a mathematician in the same sense in which I have been one, is this: that I have added something to knowledge, and helped others to add more.

G.H. Hardy (1877-1947) 
KENNISHIATEN EN TOCH BESLISSEN

Om in aansluiting op de titel van mijn rede met een flauwe grap te beginnen: Pas nu, acht jaar na mijn aantreden als hoogleraar aan de RL, heb ik mijn kennishiaten voldoende weten te camoufleren en heb ik de beslissing genomen een oratie te houden.

Mijnheer de Rector Magnificus, Dames en Heren

\section{Voorwoord}

Wat ben ik van plan $u$ in het komende half uur te vertellen. Ik hoop $u$ duidelijk te maken op welke manier de Mathematische Besliskunde en de Mathematische Besliskundige van essentiële waarde zijn ter ondersteuning van besluitvormingsprocessen in de Volksgezondheid. De Volksgezondheid, een sector waarin ieder jaar weer belangrijke keuzen moeten worden gemaakt en waarbij de hoeveelheid kennis, die de beslissingen moeten funderen slechts beperkt voorhanden is. Toch moet er beslist worden. Dit roept om een instrument dat effecten van relevante beleidsvragen kan analyseren. Ik zal dan ook een pleidooi houden voor de ontwikkeling op korte termijn van een Macromodel Volksgezondheid dat een dergelijke analysefunctie kan vervullen.

Tevens zal ik pleiten voor gerichter en intensiever onderzoek vanuit de integratieve invalshoek. Dit laatste mede om ervoor te zorgen dat ook mijn promovendi een interessante baan vinden. 


\section{Beleidskeuzen in de Volksgezondheid}

Stel u bent minister van Volksgezondheid, Welzijn en Sport en $\mathrm{u}$ krijgt het volgende beslisprobleem voorgelegd. In 1995 is er aan totale uitgaven voor de Nederlandse gezondheidszorg een bedrag van 60 miljard" gepland. minister-president Kok vraagt $\mathrm{u}$ : mag het niet een beetje minder zijn, moeilijke economische tijden, enz. En, zegt hij er bij, ik denk niet dat een reductie van $10 \%$ ten koste van de volksgezondheid hoeft te gaan, als ik zie hoeveel onnodige handelingen er in een ziekenhuis plaatsvinden.

$U$ begint na te denken ondertussen bladerend in het $F O Z^{11}$, het Financieel Overzicht Zorg. Al die getallenreeksen overziend begint u zich af te vragen wat de hoogte van de diverse kostenposten in de diverse zorgsectoren bepaald heeft. Voor een gedeelte betreft dit natuurlijk historische continuïteit, voor een gedeelte misschien wel handige onderhandelaars. Maar eigenlijk zou het toch zo moeten zijn dat de uitgaven in de diverse zorgsectoren gemotiveerd worden op basis van aanwezige zorgvraag, zeg maar geconcretiseerde zorgbehoefte, in deze sectoren. Aldus doordenkende belandt $u$ bij het punt van de werkzaamheid van de zorg. Hoe gezonder worden de mensen eigenlijk als gevolg van de medische handelingen en hoe efficiënt oefenen de medische beroepsgroepen hun vak uit.

$\mathrm{Nu}$ toch het woord gezonder gevallen is. Wat betekent dat eigenlijk? Dat mensen langer leven, of dat hun kwaliteit van leven 


\section{KENNISHIATEN EN TOCH BESLISSEN}

tijdens een chronische ziektefase verbeterd wordt, of dat gemiddeld een ziekte pas op latere leeftijd toeslaat.

Trouwens wat wil die Kok eigenlijk met dat geld dat hij bij mij weghaalt? Voor Onderwijs gebruiken of voor Cultuur. Is het niet zo dat mensen gezondheid als het belangrijkste aspect van hun leven beschouwen en dat er dus eerder meer dan minder geld naar Volksgezondheid moet?

Aldus een eerste analyse van vele vragen. Vragen en antwoorden die nauw samenhangen met beleldskeuzen. Er zijn globaal zes niveaus binnen de Volksgezondheid te onderscheiden waarop beleid gevormd wordt. Achtereenvolgens zijn dit: het regeringsniveau, niveau Ministerie VWS, niveau zorgsectoren, niveau zorginstanties, niveau beroepsgroepen, en tenslotte het niveau artsen. Deze niveaus zijn onlosmakelijk hiërarchisch met elkaar verbonden en stellen elkaars randvoorwaarden.

Daarnaast is er nog het aspect van de toekomstgerichtheid van ons gezondheidszorgsysteem. Keuzen nu begrenzen de faciliteiten in de toekomst.

\section{Kennis op Volksgezondheidsterrein}

Veel van de bovengenoemde aspecten vragen antwoorden in de vorm van kwantificaties. Kwantificaties, zeg maar getalsmatige uitdrukkingen voor criteria die de essentiële eigenschappen van het object van studie tot uitdrukking brengen. Dit veronderstelt 
KENNISHIATEN EN TOCH BESLISSEN

dat er voldoende kennis te vergaren is over het betreffende domein. Hoe zit dat op Volksgezondheidsterrein.

Veel kennis is er aanwezig op het microniveau. Verslaggevingen van artsen en specialisten over het effect van hun behandelingen zijn talrijk. Echter dit is niet de informatie die de minister van VWS nodig heeft. Daar gaat het om geaggregeerde gegevens op bevolkingsniveau. Neem een simpel uitgangspunt als jaarlijkse kosten van een bepaalde behandeling = totale volume aan behandelingen $\mathrm{x}$ kostprijs. Noch het volume is voor de meeste behandelingen goed te achterhalen, en evenmin de kostprijs, dit laatste ook al omdat in de gezondheidszorg met tarieven wordt gewerkt in plaats van met de werkelijke kosten. Even slecht is het gesteld met de kennis over het effect van medische handelingen. In direkte zin lijken medische handelingen vaak te helpen omdat de mensen weer gezond worden, maar waren ze eigenlijk nodig? En wat is het effect op de prognose? Ook hier zijn in de meeste gevallen alleen gegevens voorhanden op microniveau.

Zoals reeds gesteld, wat de minister echter nodig heeft is kennis en informatie op macroniveau, dat wil zeggen het niveau van de Nederlandse bevolking. En dan tevens in onderlinge samenhang. Neem bijvoorbeeld de vraag naar vermijdbaarheid van sterfteoorzaken. Stel dat vanaf vandaag niemand meer zou roken. Het zou mij tijdens mijn bridgeavonden welkom zijn. Natuurlijk, sterfte aan longkanker en hartinfarcten zou drastisch dalen en 
KENNISHLATEN EN TOCH BESLISSEN

wellicht zouden de mensen gemiddeld ouder worden. Maar daar vermoedelijk iedereen ooit overlijdt, zullen er dus vervangende doodsoorzaken optreden. Welke medische disciplines zijn hiervoor nodig? Wat betekent dit voor de totale uitgaven en voor het lijden van zieken? Vele vragen waarin de minister inzicht moet hebben om beslissingen te kunnen nemen, die bepalend zijn voor de kwaliteit van zorg de komende jaren.

In Nederland zijn tientallen landelijke registratiesystemen ${ }^{10)}$. De onderlinge afstemming is gering. De gegevens worden niet altijd met een bepaald doel verzameld. Het is nodig hierin meer eenheid aan te brengen. Des te meer om een Macromodel Volksgezondheid met de nodige basisinformatie te vullen. Helaas is het zo dat de minister nu maar al te vaak moet laveren in een woud van onzekerheden. Ik zou dan ook op deze plaats krachtig willen pleiten voor de ontwikkeling van een Macromodel Volksgezondheid dat de minister en met haar de volksvertegenwoordigers kan ondersteunen bij het maken van beleidskeuzen. Het is op dit punt dat de Mathematische Besliskunde aan bod komt.

Mathematische Besliskunde

Mathematische Besliskunde, een vakgebied dat begonnen is in het Bawdsey Research Station in Engeland, dat in 1939 de opdracht kreeg te onderzoeken hoe de tijdsduur tussen de eerste radarmelding van vijandelijke vliegtuigen en het moment waarop de Engelse luchtmacht in actie kwam, kon worden verkort. Het 
KENNISHIATEN EN TOCH BESLISSEN

nieuwe vakgebied kreeg de naam Operations Research. In de beginjaren concentreerde Operations Research zich in lijn met haar origine op het vinden van oplossingen voor praktische problemen. Startend in de zestiger jaren is er een periode geweest waarin de nadruk lag op de analyse van de wiskundige eigenschappen van al of niet academische probleemsituaties. Vele slimme algoritmen zijn er gepubliceerd. Misschien wel meer dan er ooit toegepast zullen worden. Ik moet bekennen, ik heb er zelf ijverig toe bijgedragen.

I $\mathrm{k}$ vind het verheugend te constateren dat de laatste jaren de Mathematische Besliskunde zich weer ontwikkelt zoals de Operations Research ooit bedoeld was en dat kernachtig omschreven is in het boek van Wagner" ${ }^{2)}$ namelijk "The art of making better decisions in a complex and uncertain environment". Dit nu zijn precies de kenmerkende aspecten van een Macromodel Volksgezondheid. Hoe kan de Mathematische Besliskunde hier zijn waarde bewijzen.

\section{Mathematische Besliskunde en projectontwikkeling}

In de eerste plaats kan de Mathematische Besliskundige optreden als een soort projectontwikkelaar. Hij kan in overleg met de inhoudsdeskundigen structuur aanbrengen in het probleemveld. Hij kan de essentiële factoren onderscheiden, hun aandrijvende mechanismen ontdekken en de aard van de diverse relaties vastleggen. Dit levert een wiskundig model op, een systeem met ob- 
jecten en relaties tussen de objecten. Het grote probleem en daardoor ook het interessante, van wiskundige modellen is dat ze abstracties van de werkelijkheid voorstellen. Niet de werkelijkheid zelf, maar iets, gedefinieerd met behulp van abstracte symbolen, wat zoveel mogelijk de werkelijkheid moet nabootsen. Hier komt dan de tweede belangrijke taak van de Mathematische Besliskundige. Hij moet uitspraken doen over de mate waarin de werkelijkheid en het wiskundig model overeenkomen, en in hoeverre het model adequate antwoorden geeft op gestelde vragen. Kortom het proces van ijken en valideren. In dit boekje heb ik een lijst van 20 items opgenomen van wat er mis kan gaan tijdens de modelleercyclus.

(20 mogelijke fouten in de modelcyclus.

1. Vergeten dat modelleren een middel is de werkelijkheid beter te begrijpen en geen doel op zich.

2. Modelleren zonder het werkelijke probleem voldoende te begrijpen.

3. Vergeten dat een model een abstractie van de werkelijkheid is.

4. Correlatie en causaliteit verwarren.

5. Verkeerd wiskundige uitdrukkingen gebruiken.

6. Onvoldoende conceptuele validering.

7. Onvoldoende aandacht voor de veronderstelling waaronder het model geldig is. 
KENNISHIATEN EN TOCH BESLISSEN

8. Niet consistente schattingen gebruiken voor te schatten parameters.

9. Nalaten de resultaten te interpreteren in het licht van het probleemdomein.

10. Slechte criteria gebruiken voor de praktische validatie.

11. Geloofwaardigheid van resultaten niet bespreken met inhoudsdeskundigen.

12. Geen balans tot stand gebracht tussen conflicterende fouten.

13. Vergeten dat het erom gaat het eenvoudigste doch adequate model te construeren.

14. Verdringen van eigen beperkingen.

15. Onvoldoende experts uit het probleemdomein raadplegen.

16. Vergeten het model goed te documenteren.

17. Onvoldoende analyse van de foutenpropagatie van numerieke oplosmethoden.

18. Onvoldoende afstemming van detailleringsniveaus bij grote projecten met werkdistributie.

19. Een stochastisch model voor een deterministisch probleem of een deterministisch model voor een stochastisch probleem.

20. Onheldere terugrapportage naar de opdrachtgevers.)

Ik zal ze $\mathrm{u}$ nu besparen, maar het validatieproces is het moeilijkste onderdeel van de wiskundige analyse van praktische pro- 
KENNISHIATEN EN TOCH BESLISSEN

blemen, maar tevens ook het meest verwaarloosde. Al te vaak verschijnen er case-studies waarbij de validatie weggemoffeld wordt. Maar het valt te verzachten: de gemodelleerde werkelijke processen zijn grillig en niet precies bekend. Het vereist kunstgrepen hieraan het model te toetsen. Strenge toetseisen leiden tot een te ingewikkeld model, niet meer geschikt voor een analyse. Anderzijds, soepele toetseisen leiden tot een te simpel model waar te weinig essentiële kenmerken van het probleemveld in verwerkt zijn. Valideren is het vinden van een trade-off tussen de twee.

De volgende fase is voor de wiskundige de meest eenvoudige, namelijk de wiskundige modelanalyse. Het opsporen van de essentiële wiskundige eigenschappen van het wiskundig model. Even kan de wiskundige zich vermaken in zijn ivoren toren. Ik zal daar later nog op terugkomen.

De volgende natuurlijke stap voor de besliskundige is de projectie van de resultaten van de modelanalyse op het probleemveld.

Besliskundige technieken en Volksgezondheidsmodellering

Welke besliskundige technieken zijn dan zoal voorhanden om de ontwikkeling van een Macromodel Volksgezondheid vorm te geven. In verkorte vorm noem ik:

1. De besliskundige als modelleur, als degene die structuur aanbrengt in het domein van de Volksgezondheid. De diver- 
se beleidsniveaus eenduidig vastlegt, de zorgsectoren afbakend, medische zorg definieert, ziekte en risicogedrag definieert en structuur aanbrengt in het vraag-aanbod mechanisme van de medische markt. Dit alles in een dynamische context. Dingen veranderen namelijk voortdurend.

2. Definiëren van de wiskundige relaties tussen de onderdelen. Bijvoorbeeld verband risicogedrag en ontstaan ziekte, nut van medische handelingen, enz.

3. Implementeren van een simulatiemodel op basis van de probleemanalyse. Voor een Macromodel Volksgezondheid moet een dergelijke implemtatie mijns inziens plaatsvinden op basis van de systeemanalytische benadering. De beschrijving moet op procesniveau plaatsvinden en een mechanistische benadering op basis van causaliteisketens of regressie uitdrukkingen voor correlaties is te beperkt.

4. Gebruik van nutsfuncties. Welk belang hechten mensen aan gezond of ziek zijn of gradaties van een invaliderende ziekte. Ook de afweging naar andere collectieve sectoren van de maatschappij kan via nutsfuncties beschreven worden.

5. Optimalisering van budgetallocaties. Welke verdeling van de beschikbare hoeveelheid geld levert de meeste gezondheidswinst op.

6. Speltheorie bij onderhandelingsprocessen en verdeelschema's. In de gezondheidszorg acteren veel belangengroepen 
KENNISHIATEN EN TOCH BESLISSEN

met niet steeds dezelfde doelstelling. De speltheorie reikt methoden aan om zekere uitkomsten van de intermenselijke processen te onderbouwen.

7. Gevoeligheidsanalyse en onzekerheidsanalyse als onderdeel van de modelanalyse. Veel relaties en parameters zijn niet precies bekend. Wat zijn de gevolgen van veranderingen hierin op de resultaten?

Een integrale benadering en de toekomstgerichtheid Ik kan niet genoeg benadrukken dat een Macromodel Volksgezondheid integraal moet zijn. Integraal in de zin dat naast objectief waarneembare processen ook subjectieve elementen in interactieve vorm meegenomen moeten worden. Binnen de Volksgezondheid spelen vele subjectieve elementen een rol. Denk aan onderhandelingsprocessen, emoties rondom ziekteprocessen, carrièreperspectieven van beleidsmakers, relatie patiënt-arts, enz. Een Macromodel waarin de sociale interacties niet verwerkt zijn, zal niet voldoen. Een belangrijk aspect zijn de zogenaamde perspectieven. Als er keuzen gemaakt moeten worden in een situatie met veel onbekende factoren, zeg maar onzekerheden, zal de keus worden bepaald door het perspectief van de beslisser met betrekking tot zijn visie op de maatschappijvorm en op de houding en onderlinge verhoudingen van de individuele burgers. Bij het $\mathrm{RIVM}^{6 \mathrm{j}}$ is recentelijk het perspectievenconcept zoals door Thompson ontwikkeld in de milieumodellen ingevoerd. Dit hoort 
KENNISHIATEN EN TOCH BESLISSEN

zeker ook thuis in een macromodel Volksgezondheid. Een eerste aanzet tot toepassing van het perspectievenconcept is overigens reeds te vinden in de studie van Lapre $e^{7 /}$ naar de Toekomstige Bestuurlijke Ordening in de Gezondheidszorg.

\section{Toekomstscenario's}

Het Macromodel Volksgezondheid moet toekomstscenario's kunnen construeren en op hun effecten toetsen ten aanzien van medische handelingen, gezondheidseffecten en kosten. Binnen Nederland is de nodige expertise opgebouwd ten aanzien van het scenariodenken.

Het was in 1983 dat de toenmalige minister van WVC de Stuurgroep Toekomstscenario's Gezondheidszorg (STG) ${ }^{8)}$ installeerde. De belangrijkste doelstelling was een beeld te geven van mogelijke en wenselijke toekomstige ontwikkelingen op het terrein van de Volksgezondheid en de gezondheidszorg. De STG heeft deze doelstelling trachten te bereiken via het uitzetten van projecten in diverse gebieden van de gezondheidszorg. Zo waren er projecten met betrekking tot Vergrijzing, Medische Technologie, Ongevallen, Kanker, Coronaire Hartziekten ${ }^{9)}$ en Eerstelijns-Gezondheidszorg.

Voor het denken over de inrichting van de zorg in Nederland nu en in de toekomst zijn deze studies bijzonder belangrijk geweest. Om twee redenen zijn de STG-studies mijns inziens minder geschikt om beleidsbeslissingen te ondersteunen. De eerste betreft 


\section{KENNISHIATEN EN TOCH BESLISSEN}

het feit dat ieder van deze studies zich afspeelt op een deelterrein van de gezondheidszorg. Alleen integrale benaderingen zullen het gehele veld kunnen overzien.

De tweede reden van de beperkte bruikbaarheid van de STGstudies betreft het feit dat in de meeste van deze studies er geen direkte relaties uitgewerkt zijn tussen de drie-eenheid medische activiteiten, gezondheidseffecten en kosten. U zult zich hebben gerealiseerd in uw overwegingen met betrekking tot de vraag van Kok dat $u$ graag wilt weten hoe duur medische activiteiten zijn en wat ze opbrengen aan gezondheidswinst.

Te vroeg mijns inziens is de STG in haar oorspronkelijke vorm opgeheven. Als Stichting bestaat de STG weliswaar nog, maar sinds de financiële injecties vanuit het Ministerie van VWS geminimaliseerd zijn is de armslag te beperkt. Juist nadat de deelstudies veel basiskennis en informatie hadden opgeleverd was het moment aangebroken tot integratie over te gaan. De STGactiviteiten hebben ervoor gezorgd dat Nederland toonaangevend is op het gebied van inzicht in de fundamentele processen rondom het fenomeen ziekte in relatie tot de gezondheidszorg als systeem. Het is nu tijd om de opgebouwde expertise verder uit te bouwen.

Dit is des te meer van belang omdat de gestelde vraag van de minister-president met betrekking tot bezuinigingen geen ondenkbeeldige is. Steeds meer groeit het besef dat de grenzen aan de uitgaven in de zorg bereikt zijn. Aan de andere kant ontwik- 
KENNISHLATEN EN TOCH BESLISSEN

kelt de medische wetenschap zich pijlsnel. Groeit het aantal technische mogelijkheden, met name dure en stellen de mensen zich steeds krachtiger als kwaliteit eisende consument van zorgaanbod op.

Een instrument dat toekomstige onzekerheid ten aanzien van effecten van beleidskeuzen kan minimaliseren is onmisbaar in het licht van deze ontwikkelingen.

Tot zover mijn beschouwing over de relevantie van de Mathematische Besliskunde voor een Macromodel Volksgezondheid.

\section{De Wiskunde}

Laat $u$ niet verleiden door mijn rede van vandaag dat wiskundigen en wiskunde zich met praktische problemen bezig houden. Het tegengestelde is juister. Wiskunde is systematische redeneringen houden binnen abstracte systemen. Startende met een aantal axioma's, de onbewezen of onbewijsbare uitgangspunten, gebruik makende van wat toegestane logische redeneringen zijn, is de wiskundige op zoek naar steeds nieuwe waarheden binnen zijn systeem. Hij noemt dit stellingen. Er komen er per jaar minstens 200.000 stellingen bij. De wiskundige maakt zich geen zorgen of deze stellingen in de praktijk bruikbaar zijn en dat is maar goed ook, anders was het Andrew Wiles ${ }^{3 /}$ recentelijk nooit gelukt om de laatste stelling van Fermat te bewijzen, als zijn bewijs tenminste klopt. 


\section{KENNISHIATEN EN TOCH BESLISSEN}

Voor de ontwikkeling van de wiskunde is het niet te hopen dat de mythe van de directe maatschappelijke relevantie van wetenschappelijk onderzoek ook de fundamentele wiskundigen te pakken zal krijgen. Reeds in diverse wetenschapsgebieden zie je een zekere vervlakking van het onderzoek ontstaan. Output gericht, snel scoren, publicaties tellen, risico vermijden, defensief publiceren, vooral motiveren (al of niet kunstmatig) vanuit direkte relevantie. Het is een trend die vanaf de zeventiger jaren gaande is maar die vooral de afgelopen jaren aangescherpt is door de onduidelijke evaluatiemechanismen. Ook de introductie van de onderzoeksscholen heeft geleid tot een versterkte aandacht voor het fenomeen impressiemanagement (met dank aan Peter Braspenning voor deze term). De boot mag niet gemist worden.

Niemand kan tegen evaluatie van onderzoek zijn, maar laat dat dan gebeuren aan de hand van wetenschapstak specifieke definities van wat goed en gewenst onderzoek is. Ik heb reeds aangegeven dat dit voor de wiskunde extra problematisch is daar op zijn minst een gedeelte van het onderzoek niet getoetst kan en mag worden op direkte maatschappelijke relevantie.

\section{Kennistechnologie}

Tot slot wil ik nog iets zeggen over de opleiding Kennistechnologie. Kennistechnologie ${ }^{4)}$ is een coproduktie van de Rijksuniversiteit Limburg en het Limburgs Universitair Centrum te Diepenbeek. De beide eerste jaren vinden grotendeels aan het LUC 
KENNISHIATEN EN TOCH BESLISSEN

plaats en de jaren 3 en 4 aan de RL. Zoals de naam van de opleiding reeds uitdrukt gaat het bij Kennistechnologie om het in technische zin omgaan met kennis, vooral vanuit de vakgebieden Informatica en Wiskunde. Voor de Informatica betreft dit de vakken Kennissystemen, Logische Redeneermechanismen en Methoden uit de Kunstmatige Intelligentie. Voor de Wiskunde zijn dit de Systeemtheorie, Mathematische Besliskunde en Statistiek. Tijdens de beide eerste jaren aan het LUC ligt de nadruk logischerwijs op een aantal fundamentele vakken. Als $u$ er meer van wilt weten, raad ik $\mathrm{u}$ aan zich in te schrijven, het is een uitermate boeiende studie. Tot zover niks nieuws. Waarom ik het punt onderwijs aanroer komt door de wijze waarop we de studiejaren 3 en $4^{5)}$ gestalte hebben gegeven. We hebben een studiejaar opgedeeld in 4 perioden van 10 weken. Per periode richt de studie zich op een bepaald thema. Dus 4 thema's per jaar. Studenten worden opgedeeld in groepjes van 4 à 5 studenten. Per groep moeten de studenten gezamelijk een project uitvoeren in zo'n periode van 10 weken. Een vaste stafmedewerker staat met raad en daad terzijde. Als project moet $u$ bijvoorbeeld denken aan het ontwikkelen en implementeren van een Macromodel Volksgezondheid, of aan een model voor de verspreiding van vervuilende chemicaliën in de Maas, of aan transportplanning voor de ENCI. Het gaat om projecten waar veel kennis een rol speelt en waar de genoemde Wiskunde- en Informaticatechnieken "iets" met deze kennis doen. 
De helft van de beschikbare tijd kunnen de studenten aan het project besteden, de andere helft zijn er klassieke hoor- en werkcolleges die mede ondersteunend zijn voor het project.

Voor een bèta-opleiding is dit onderwijssysteem uniek in Nederland. Het valt te beschouwen als een variant op het bekende Maastrichtse PGO-systeem.

De verdiensten van ons onderwijssysteem zijn legio.

Ik noem er slechts vier.

1. Studenten leren tijdens hun studie met praktische problemen om te gaan.

2. Studenten leren gezamelijk aan één project te werken.

3. De voorbeeldfunctie van docenten blijft behouden. Dit is vooral van belang voor een op een abstract begrippenkader gebaseerd vak als Kennistechnologie.

4. Studenten herkennen het nut van het geleerde door de praktische toepassing en zijn daardoor beter gemotiveerd.

We hebben dit onderwijssysteem een beetje afgekeken van de Technische Universiteit van Aalborg in Denemarken waar het in alle afdelingen toegepast wordt $t^{5}$.

Ik ben ervan overtuigd dat onze onderwijsmethode voor vele zo niet alle natuurwetenschappelijke en technische opleidingen een goede methode is. Integratief leren denken, beseffen dat sociale en mechanistische processen in de praktijk voortdurend samenspelen en weten dat er informatica- en wiskunde technieken voorhanden zijn om met kennis te stoeien. Het enige nadeel is 
dat het nogal wat onderwijscapaciteit vraagt. Desondanks zou ik de dames en heren studenten willen oproepen actief zoveel mogelijk kennis te onttrekken aan de docenten. Kennisextractie is per slot van rekening een belangrijk onderdeel van de studie.

\section{Tenslotte}

Aan het eind van deze rede wil ik een aantal personen bedanken die een beslissende invloed op mijn leven hebben gehad.

Ik heb deze rede opgedragen aan mijn helaas te vroeg overleden ouders en aan mijn broer Harry. Pas later ben ik me ervan bewust geworden hoe onze manier van leven, op die kleine boerderij, voor mij een voorbeeldfunctie vervuld heeft, niet alleen waarden en normen aanreikend maar ook zekerheid en vertrouwen, en dit alles onder het credo: "Nait soez'n maor doun".

Het College van Bestuur wil ik danken voor het vertrouwen in mij uitgesproken via de benoeming, destijds.

Hooggeleerde De Leve, beste Gijs.

Als hoofd van de Sectie Mathematische Besliskunde van het toenmalige Mathematisch Centrum (nu Centrum voor Wiskunde en Informatica) heb je de mathematische besliskunde in Nederland vorm gegeven. Op dit moment zijn er minstens 6 hoogleraren op Besliskunde gebied die uit jouw groep voortgekomen zijn. 
Anton en ik zijn er twee van. De wijze waarop jij de onderzoekers de mogelijkheid bood zich te ontwikkelen heeft me zeer aangesproken. Ik moet bekennen dat ik tracht je stijl van leiding geven over te nemen.

Hooggeleerde Tijms, beste Henk.

Als promotor heb je veel voor mij betekend. Jouw oprechtheid en no-nonsense stijl hebben bij mij veel waardering geoogst. Ook al zien we elkaar de laatste tijd niet meer zo vaak, het contact blijft immer op vriendenniveau.

Hooggeleerde Tijs, beste Stef.

Als voorvader van speltheoretisch Nederland heb je mij in je kielzog meegezogen. Ik ben je daar dankbaar voor en ga er vanuit dat we nog in lengte der dagen zullen samenwerken.

Dames en heren van de Vakgroep Wiskunde.

Wat de vakgroep bereikt heeft, heb niet ik bereikt maar wij samen. Veel dank voor de regelmatig onregelmatige inzet.

Olga en Els.

Twee verschrikkelijk fijne dochters die immer bereid zijn mij te helpen bij de praktijk van de speltheorie. 


\section{KENNISHIATEN EN TOCH BESLISSEN}

Sieneke.

Ideeën. Inspiratie en Liefde. Meer hoef ik niet.

Ik heb gezegd. 
KENNISHIATEN EN TOCH BESLISSEN

\section{Literatuur}

1) Financieel Overzicht Zorg 1995, Tweede Kamer, Vergaderjaar 1994-1995, 23904 nrs. 1-2

2) Wagner, H.M., "Principles of Operations Research", 1969. Prentice-Hall, Inc.

3) Wiles, A., "Modular Elliptic Curves and Fermat's last Theorem", 1995, Annals of Mathematics, 141(3), pp 443-552

4) Faculteit der Algemene Wetenschappen, Kennistechnologie, Studiegids 1995-1996, Rijksuniversiteit Limburg

5) Perrenet, J., Weijters, A., and Koehorst, A., "A Project Oriented Curriculum in Knowledge Engineering: The Maastrichts Alternative", 1995, To appear in Proceedings of the AISB Workshop on AI Education

6) Asselt, M. van, Rotmans, J., "Uncertainty in integrated Assessment Modelling, a cultural perspective-based approach", GLOBO, Report Series no. 9, 1995, RIVM

7) Lapré, R., "Gezondheidszorg Geordend; een kwartet Scenario's", 1995, STG-rapport, STG, Zoetermeer

8) Stuurgroep Toekomstscenario's Gezondheidszorg, Structuur en Opdracht, STG, 1987, Van Arkel, Utrecht

9) Vrieze, O.J., Boas, G.M., Janssen, J.H.A., "Een simulatiemodel voor toekomstanalyse van coronaire hartziekten", STG, 1994, Van Arkel, Utrecht

10) Tellen en meten; een overzicht van landelijke registraties in de zorg, 1993, Ministerie van WVC 